\title{
Die ungarische Testamentsforschung, mit besonderer Berücksichtigung der dörflichen Testamente. Ein Literatur- und Forschungsbericht*
}

Die Vorgeschichte der ungarischen Testamentsforschungen reicht bis zum Ende des 19. Jahrhunderts zurück. Bis dahin erschienen nur vereinzelte Publikationen in wissenschaftlichen Zeitschriften. ${ }^{1}$ Die erste wesentliche Arbeit war ein Werk von Baron Béla Radvánszky. ${ }^{2}$ In seinem Quellenwerk veröffentlichte er 49 Testamente von Hochadeligen. Damit liegen wichtige Angaben zu den Forschungen der Geschichte dieses Standes vor.

Die erste bedeutende Arbeit zu Testamenten von Stadtbürgern stammt aus dem Jahr 1930: Jenő Házi, Hauptarchivar von Ödenburg [Sopron], veröffentlichte 313 Ödenburger Testamente aus dem Spätmittelalter. Sie erschienen in ihrer ursprünglichen Sprache, in frühem neuhochdeutschem Dialekt. ${ }^{3}$

Eine Publikation von Ernő Tárkány Szücs von 1961 war die erste Quellenausgabe von Testamenten aus Marktflecken. ${ }^{4}$ Seine einleitende

\footnotetext{
* Übersetzt von Ilona Mészáros-Sipos.

${ }^{1}$ Mehrere Quellenausgaben erschienen zum Beispiel in der Zeitschrift „Tudományos Gyűjtemény” (erschien in Pest zwischen 1817 und 1841); vgl.: CsÉCS, Tudományos Gyüjtemény.

${ }^{2}$ RADVÁNSZKY, Magyar családélet.

${ }^{3}$ HÁZI, Sopron története II, 1-2.

${ }^{4}$ TÁRKÁNY SzÜCS, Vásárhelyi testamentumok.
}

Studie $^{5}$ wurde ein grundlegendes Kompendium für alle weiteren Forschungen.

Der Aufschwung der ungarischen Testamentsforschung begann Mitte der 80er Jahre; seitdem erschienen mehrere Dutzend Quellenwerke und mehrere Hundert analytische Studien zu diesem Thema. Im Nachfolgenden möchte ich auf die wichtigsten Studien hinweisen, die ich nach dem untersuchten Zeitalter gruppiere.

Auf den historischen Quellenwert der Testamente des späten Mittelalters machte László Solymosi aufmerksam. Seine Studie von 1974 berührt mehrere in rechtsgeschichtlicher Hinsicht wichtige Fragen. ${ }^{6}$ Unter den Forschern, die sich mit adeligen und hochadeligen Testamenten beschäftigen, möchte ich András Kubinyi erwähnen. Er ist zu wichtigen Ergebnissen gekommen, besonders über Testamente, die von der Wende des 15. zum 16. Jahrhundert, aus der sogenannten Jagello-Zeit, stammen. Besonders wichtig ist seine Studie, in der er 13 hochadelige und 37 adelige Testamente analysiert.7 Er untersucht die typischen Charakterzüge dieser Quellentypen und hat deren wichtigsten Inhalte zusammengefasst.

\footnotetext{
${ }^{5}$ Ebd. 5-291.

${ }^{6}$ SOLYMOSI, Középkori végrendeleteink.

${ }^{7}$ KUBINYI, Főúri végrendeletek.
} 
Katalin Szende ist eine Schülerin von András Kubinyi. Sie hat in den letzten zwei Jahrzehnten am allermeisten im Bereich der Testamentsforschung getan. Ihre Laufbahn begann 1990 mit der Analyse der Ödenburger Testamente, die Jenő Házi veröffentlicht hatte. ${ }^{8}$ Besonders bedeutend war ihr Aufsatz über die materielle Kultur des Bürgertums von Ödenburg. ${ }^{9}$ Einige Jahre später beschäftigte sie sich mit spätmittelalterlichen Testamenten aus Pressburg [Bratislava, Poszony]. In mehreren Aufsätzen verglich sie erhalten gebliebene Testamente aus beiden Städten. ${ }^{10}$ Ich möchte nur zwei Themen aus dem sehr umfassenden Werk von Katalin Szende hervorheben. 1997 erschien ihr Aufsatz zu Familienstruktur und Erbgewohnheiten des späten Mittelalters in Ödenburg und in Pressburg. ${ }^{11}$ Zwei Jahre später beschäftigte sie sich mit der Bedeutung städtischer Testamente in der europäischen Rechtspraxis.12 Sie bezog dabei auch die Stadt Eperjes [Prešov] in die zu untersuchenden Städte mit ein. Die wichtigsten Ergebnisse ihrer 15-jährigen Forschungsarbeit hat sie in ihrem Werk „Zu Hause in der Stadt. Gesellschaft und materielle Kultur im mittelalterlichen Ödenburg, Pressburg und Eperjes" zusammengefasst. ${ }^{13}$ Dieses Buch ist im Jahre 2004 erschienen, und ich kann es allen Testamentsforschern als unentbehrliches Nachschlagewerk empfehlen. Es ist auch für Historiker, Ethnologen, Soziologen, überhaupt für alle, die sich für das Leben früherer Zeiten interessieren, gleichermaßen relevant. Das grosse Wissen der Autorin wird in der Bibliographie, die aus 410 Titeln besteht, deutlich. Mehr als die Hälfte der Titel enthält

\footnotetext{
${ }^{8}$ SZENDE, A soproni végrendeletek; SZENDE, Handwerkerwitwen.

${ }^{9}$ SZENDE, Soproni polgárság kultúrája.

${ }^{10}$ Zum Beispiel: SZENDE, es sey vil oder wenig; SZENDE, A nők szerepe.

${ }^{11}$ SZENDE, Családszerkezet.

12 SZENDE, A magyarországi városi végrendeletek helye.

${ }^{13}$ SZENDE, Otthon a városban.
}

ausländische Fachliteratur, fast aus ganz Europa. Thre Zusammenfassung gründet sie auf ihre eigenen 27 Studien. Von diesen Studien sind acht auf Englisch und drei auf Deutsch erschienen, zum Teil in ausländischen Publikationen. Auch die Menge der von ihr bearbeiteten Quellen ist beachtenswert: ihre Analyse spätmittelalterlicher Testamente beruht auf 314 Testamenten aus Ödenburg, 883 aus Pressburg und 122 aus Eperjes.

Ich könnte noch lange Verdienste von Katalin Szende aufzählen, aber ich möchte nur darauf aufmerksam machen, dass sie als Professorin der Mitteleuropischen Universität in Budapest viele junge Leute zur Testamentsforschung brachte. Einige ihrer Schülerinnen haben als Forschungsthema spätere Zeitalter gewählt. Judit Majorossy konnte aber in ihrer Arbeit die Edition spätmittelalterlicher Testamente aus Pressburg verwenden. ${ }^{14}$ Mária Lupescu-Makó versuchte unter anderem die fachhistorischen Erfahrungen aus der Arbeit mit den Testamenten adeliger Siebenbürger aus dem späten Mittelalter zusammenfassen. ${ }^{15}$

Ich möchte mich primär mit städtischen Testamenten aus der Frühen Neuzeit beschäftigen, aber kurz auch die Testamente von Adeligen und kirchlichen Personen behandeln.

Im Bereich der Veröffentlichung städtischer Testamente aus dem 16.-17. Jahrhundert hat Gábor Németh den ersten Schritt getan. ${ }^{16}$ Seine Quellenausgabe erschien im Jahre 1995. Er hat 90 Bürgertestamente aus der Stadt Tyrnau [Trnava, Nagyszombat] aus der Zeit zwischen 1542 und 1690 veröffentlicht. Wenn man die Lage der Stadt in dieser Zeit und die Rolle der Einwohner kennt und berücksichtigt, schätzt man die Wichtigkeit des Bandes.

\footnotetext{
${ }^{14}$ Majorossy, A Krisztus Teste Konfraternitás helye.

${ }^{15}$ LUPESCU-MAKÓ, Erdélyi nemesi végrendeletek.

${ }^{16}$ NÉMETH, Nagyszombati testamentumok.
} 
Gábor Németh hat in einem weiteren Quellenwerk 64 aus der Stadt Gyöngyös stammende Testamente und Nachlassbriefe aus der Periode zwischen 1642 und 1710 ediert. ${ }^{17}$ Die Besonderheit dieses Bandes ist, dass die Quellen im Archiv der reformierten Kirche geblieben sind; so gelang es - dank den Franziskanern - auch während der Eroberungszeit den letzten Willen der zur Minderheit gehörenden Menschen in den katholischen Gemeinden für die Nachwelt sicher zu stellen.

Aus Kecskemét sind Testamente seit dem 17. Jahrhundert erhalten. Tibor Iványosi-Szabó hat 32 vor 1700 verfasste Testamente veröffentlicht. ${ }^{18}$ Aus dieser Zeit sind in Debrecen nur 16 Testamente erhalten geblieben, und nur eines wurde bisher veröffentlicht. ${ }^{19}$

Von den in Raab [Győr] erhalten gebliebenen Testamenten aus dem 17. Jahrhundert habe ich 350 in drei Bänden veröffentlicht. ${ }^{20}$ Dies ist nur ein Drittel der vorhandenen Quellen. 90 Prozent der edierten Testamente stammen von in Győr lebenden Personen, 10 Prozent aus anderen Orten; hauptsächlich aus einer Leibeigenengemeinde, die zu der Herrschaft des Raaber Domkapitels gehörte - die ich noch ausführlich behandeln werde. Auf den Quellenwert der Raaber Testamente habe ich in den letzten zwei Jahrzehnten oft aufmerksam gemacht. Ich habe die Beziehungen der Familien, die Bestattungsgewohnheiten, oder auch die Rolle der Schriftlichkeit untersucht. ${ }^{21}$ Es war auch interessant, die Testamente von Handwerkern oder die der Elite der Stadt zu untersuchen. ${ }^{22}$ Besonders erwähnenswert sind die Testamente der in der Stadt lebenden Fremden, besonders die der Deut-

${ }^{17}$ NÉMETH, Gyöngyösi testamentumok.

18 IVÁNYOSI-SZABÓ, Kecskeméti testamentumok 1.

${ }^{19}$ RÁCZ, Debreceni végrendeletek.

${ }^{20}$ HoRVÁTH, Győri végrendeletek a 17. századból.

${ }^{21}$ HORVÁTH, 1600-1630 győri végrendeletek; HoRVÁTH, Temetkezési szokások; HORVÁTH, Írásbeliség.

${ }^{22}$ HorvátH, Győri iparos végrendeletek; HoRvÁTH, Győr bírái. schen. ${ }^{23}$ Sie haben ihre Rechtsgewohnheiten mitgebracht und diese Gewohnheiten hier weiterleben lassen.

Zwei Publikationen aus den letzten beiden Jahren beschäftigen sich mit Ödenburg: Erstens der wertvolle, zweisprachige Band von Peter Dominkovits über den Bürgermeister Christoph Lackner. ${ }^{24}$ In diesem Band erschienen die Testamente Christoph Lackners, seiner Frau und seines Vaters. Im Buch findet man ein Inventar, eine Aufstellung seines Vermögens und seine Aufzeichnungen über Stiftungsbeiträge.

Ebenfalls zweisprachig ist die Publikation von Anita D. Szakács über Ödenburger medizingeschichtliche Testamente. ${ }^{25}$ Szakács hat aus dem Archiv Ödenburg Testamente von Ärzten, Chirurgen, Apothekern und Hebammen aus der frühen Neuzeit zusammengefasst. Das Buch enthält eine deutschsprachige Abhandlung und fast hundert Quellen. Die älteste Quelle stammt aus dem Jahre 1544, die letzte von 1787. Damit ist nach Meinung der Verfasserin das gesellschaftliche Sanitätswesen der Stadt umfassend repräsentiert.

Mit Testamenten römisch-katholischer Kleriker aus der frühen Neuzeit hat sich die ungarische historische Forschung bisher kaum beschäftigt. Ich kann nur den Aufsatz von Péter Dominkovits erwähnen, in dem er zwei Pfarrertestamente vom Ende des 17. Jahrhunderts ediert hat. ${ }^{26}$ Diese Testamente stammen aus dem Dorf Hidegség im Komitat Ödenburg.

Bezüglich der adeligen Testamente aus dem 16. und 17. Jahrhundert ist festzustellen, dass seit dem Werk von Béla Radvánszky keine vergleichbare Publikation mehr erschienen ist. Die Quellenausgaben adeliger Testamente habe auch ich vermehrt, indem ich mit Péter Domin-

\footnotetext{
${ }^{23} \mathrm{Vgl}$. HORVÁTH, Győri végrendelkezők.

${ }^{24}$ DOMINKOVITS, Egy gazdag városvezető.

${ }^{25}$ SZAKÁCS, Medizingeschichtliche Testamente.

${ }^{26}$ DOMINKOVITS, Pfarrertestamente aus Hidegség.
} 
kovits ungefähr 50 Testamente aus dem Komitat Ödenburg aus dem 17. Jahrhundert ediert habe. ${ }^{27}$ In einer einleitenden Studie habe ich mich mit rechtlichen Besonderheiten (zum Beispiel der Geltendmachung von Sonderrechten der Frauen) beschäftigt. Ich möchte eindringlich darauf hinweisen, dass aus den Testamenten hervorgeht, dass die Testatoren über juristische Kentnisse verfügten.

Aus dem Bereich der adeligen Testamentsforschungen zur frühen Neuzeit möchte ich auch auf die Serie siebenbürgischer Testamente aufmerksam machen, die seit 2003 in Târgu Mureș [Marosvásárhely] erschienen. Kinga Tüdős veröffentlichte im ersten Band die Testamente 138 kriegsführender Szekler; ${ }^{28}$ die beiden weiteren Bände enthalten insgesamt 117 Testamente Adeliger und wichtiger Personen. Diese stammen hauptsächlich aus der zweiten Hälfte des 16. und aus der ersten Hälfte des 17. Jahrhunderts. ${ }^{29}$

Aus dem 18. und 19. Jahrhundert wurden vor allem städtische Testamente publiziert. Es ist nicht möglich, die zahlreichen selbständigen Quellenwerke alle zu erwähnen. Ich möchte nur einige hervorheben. Es ist bemerkenswert, dass sich der grösste Teil der Publikationen mit der grossen ungarischen Tiefebene beschäftigt. Die Stadt Kecskemét hat die Führungsrolle; bis jetzt erschienen in vier Bänden etwa 1500 Testamente aus dieser Stadt. Der Herausgeber Tibor Iványosi-Szabó hat ursprünglich bei der Veröffentlichung der Quellen Vollständigkeit angestrebt. Entsprechend seiner Absicht erschienen in den ersten beiden Bänden fast 900 Testamente aus der Zeit vor $1781 .{ }^{30}$ Später musste er wegen des grossen Umfangs einzelne Testamente auswäh-

\footnotetext{
${ }^{27}$ HoRvÁth, DOMINKOvITS, 17. századi Sopron vármegyei végrendeletek.

28 TÜDÖs, Erdélyi testamentumok 1.

${ }^{29}$ TÜDÖS, Erdélyi testamentumok 2; TÜDÖs, Erdélyi testamentumok 3.

${ }^{30}$ IVÁNYOSI-SZABÓ, Kecskeméti testamentumok 1; IVÁNYOSI-SZABÓ, Kecskeméti testamentumok 2.
}

len. ${ }^{31}$ Das Stadtarchiv von Vác strebt die Ausgabe der dort erhaltenen Testamente an. Der einzige bis jetzt erschienene Band enthält 165 Testamente aus der ersten Hälfte des 18. Jahrhunderts. ${ }^{32}$

Andere Forscher mussten schon am Anfang Quellen auswählen. So konnten zum Beispiel aus den Städten Debrecen, Nyíregyháza, Cegléd oder Jászberény die aus dem 18. und 19. Jahrhundert erhalten gebliebenen Testamente nur zum Teil erscheinen. ${ }^{33}$ Ich möchte auf die Quellenausgabe von Nyíregyháza aufmerksam machen. Der erste Teil des von Zoltán Németh herausgegebenen Buches enthält 52 Testamente sowohl in der ursprünglichen Sprache (slowakisch) als auch in ungarischer Übersetzung. ${ }^{34}$

In einigen Werken sind Testamente aus verschiedenen Städten zusammengestellt. Zum Beispiel hat János Kemény 186 Testamente aus sechs Marktflecken aus dem Donau-Theiss Gebiet aus dem Zeitraum zwischen 1738 und 1847 herausgegeben. ${ }^{35}$ In den Archiven dieser Siedlungen erhalten gebliebene Testamente konnten nur zum Teil erscheinen. Zum Beispiel konnten von 600 aus Kiskunhalas aus der Zeit vor 1848 erhalten gebliebenen Testamenten nur 35 veröffentlicht werden, ${ }^{36}$ aber auch diese sind eine grosse Hilfe für die Forschung.

Ich möchte die Tätigkeit zweier Forscherinnen erwähnen, deren Methoden von denen der bis jetzt erwähnten Forscher abweichen. Mónika Mátay hat ihre Forschung auf das "Nachleben“ des Testamentes erweitert. Dazu sind die Akten

\footnotetext{
31 IVÁNYOSI-SZABÓ, Kecskeméti testamentumok 3; IVÁNYOSI-SZABÓ, Kecskeméti testamentumok 4.

32 HorvátH, Váci végrendeletek 1.

${ }^{33}$ RÁCZ, Debreceni végrendeletek; NÉMETH, Testamentumok, osztályos egyezségek Nyíregyházán; KUJBUSMeCSEI, Nyíregyházi testamentumok; KocsIS, 18. századi ceglédi végrendeletek; KocsIS, Hagyatéki iratok; CZÉGÉNY, Jászberényi végrendeletek.

${ }^{34}$ NÉMETH, Testamentumok.

${ }^{35}$ KEMÉNY, Mezővárosi végrendeletek.

${ }^{36}$ Vgl. HoRvÁTH, Végrendelkezés Halason.
} 
von Scheidungsprozessen die besten Quellen. Die Verfasserin wendet juristische und antropologische Methoden an. Sie hat nach mehreren kleinen Studien ${ }^{37}$ im Jahr 2002 ihre Dissertation über Testamente und Nachlassprozesse in Debrecen im 18. und 19. Jahrhundert geschrieben. ${ }^{38}$ Einige Jahre später erschien von ihr auch eine Untersuchung der Akten von Scheidungsprozessen in Debrecen. ${ }^{39}$

Ich halte auch die Forschungen von Ildikó Kristóf für sehr interessant. Sie hat in ihrem Werk „Normen und Formen der Disposition in den Dörfern und in den Marktflecken im 16-17. Jahrhundert" nicht die Testamente untersucht, sondern den Ritus der Testierung. ${ }^{40}$ Sie hat mehrere Dutzend Werke aus der alten ungarischen Literatur untersucht, die sich mit der ars morien$d i$ (Kunst des Sterbens) und der ars bene vivendi (Kunst des guten Lebens) beschäftigen. Ihre Ergebnisse sind überdenkenswert für alle Testamentsforscher.

Ich möchte auch auf das 2008 erschienene Buch von István Kelemen, einem Historiker in Ödenburg aufmerksam machen, das sich mit der Erforschung dörflicher Testamente beschäftigt. ${ }^{41}$ Das Buch enthält Testamente Leibeigener aus dem Komitat Ödenburg vom Anfang des 18. Jahrhunderts bis zum Jahr 1848. Ich mache besonders auf die gründliche einleitende Studie aufmerksam. ${ }^{42}$ Sie beschäftigt sich ausführlich mit den Möglichkeiten der Testatoren und mit den Beschränkungen der Testierung. Er untersucht die Rechte der Gutsherren, der Witwen und der Ledigen. Außerdem analysiert er die Struktur der Testamente, die Eigenschaften der

\footnotetext{
${ }^{37}$ MÁtAy, Barta Gergely; MÁtAy, Egy tímármester utolsó akarata.

${ }^{38}$ Vgl. MÁTAY, Historiográfiai viták a testamentumokról 269.

${ }^{39}$ MÁTAY, Törvényszéki játszmák.

${ }^{40}$ KRISTÓF, Rendeld el házadat, mert meghalsz.

${ }^{41}$ KELEMEN, Sopron vármegyei jobbágyvégren-deletek.

${ }^{42}$ Ebd. 13-88.
}

Einleitung, der inhaltlichen Bestimmungen und Klauseln.

Die Publikation ist bemerkenswert, weil István Kelemen der einzige ungarische Forscher ist, der sich so ausführlich mit Testamenten von Leibeigenen beschäftigt. Allerdings hat sich auch der hervorragende Rechtshistoriker Ernő Tárkány Szücs in mehreren Publikationen mit diesem Thema beschäftigt. ${ }^{43}$

Ich wurde auf den Quellenwert der dörflichen Testamente aufmerksam, als ich die Testamentsammlung des Archives des Raaber Domkapitels vor zwei Jahrzehnten eingehender durchsah. Ich untersuchte zum Raaber Domkapitel gehörende Dörfer, aus denen Testamente erhalten geblieben sind. Ich fand sechs Testamente, die in Káptalanvis im Komitat Ödenburg aufgenommen wurden. Das früheste Testament stammt aus dem Jahr 1600, das späteste aus dem Jahr 1693. Dem Inhalt der Testamente konnte ich unbekannte Angaben über die Geschichte des Dorfes entnehmen, wie etwa bisher unbekannte Namen und Tätigkeiten der zwei Pfarrer und fünf Dorfrichter. Weiters fand ich zwei Angaben über den Schulmeister von Vis, und konnte was ich für das Wichtigste halte - 86 Einwohner aus Vis namentlich kennenlernen. In den Quellen werden sechs als Testatoren, 41 als Zeugen, 13 als Familienmitglieder, acht als Schuldner, 14 als Gläubiger und vier in anderer Funktion erwähnt. Ich habe mehr als ein Dutzend Flurnamen aus Vis gefunden, die in anderen Quellen nicht vorkommen. ${ }^{44}$

Lehrreich war auch meine Erforschung der Testamente aus Nyúl, einer Nachbargemeinde von Raab. Ich fand vier Testamente aus diesem Ort. Aus den Quellen konnte ich 31 Namen entnehmen. Neben vier Testatoren handelt es sich dabei um drei Verwandte, 21 Zeugen und drei

\footnotetext{
${ }^{43}$ TÁRKÁNY SZÜCS, A jobbágy végrendelete; TÁRKÁNY SZÜCS, Makói parasztok végrendeletei; TÁRKÁNY SZÜCS, Népszokások.

${ }^{44}$ HoRvÁtH, Káptalanvisi végrendeletek.
} 
weitere Namen. Diese Quellen enthalten wichtige Informationen zur zeitgenössischen Ortsgeschichte und zum Gemeindeleben. Sie geben ein Bild von der Abstammung des Erblassers, von seinen familiären und verwandtschaftlichen Beziehungen, von seinem Vermögensstand und seinen Schulden. Wir können einige Vorgesetzte kennenlernen. Diese Daten werden durch die Angaben aus Raaber Testamenten ergänzt, die vereinzelt interessante Fakten über die Gemeinde Nyúl oder ihre Einwohner enthalten. Ich halte es für erwähnenswert, dass Raaber Bürger Weingärten in Nyúl hatten. Aus den Raaber Testamenten gehen mehr als 50 Namen der Einwohner von Nyúl hervor. ${ }^{45}$

Unter den im Archiv des Raaber Domkapitels erhaltenen Testamenten stammen viele aus dem Marktflecken Weiden [Védeny] im Komitat Wieselburg [Moson]. Aus diesem Marktflecken fand ich 32 Testamente. Das erste davon stammt aus dem Jahre 1583, das letzte von 1719. Der grösste Teil der Quellen ist deutschsprachig, der Rest lateinisch. Diese Quellen wurden bisher von der geschichtlichen Forschung noch nicht aufgearbeitet.

Meine Forschungen zu dörflichen Testamenten aus dem 17. und 18. Jahrhundert weitete ich auf einige andere Archive aus. Ich fand sehr interessante Quellen im Archiv der Benediktiner Erzabtei in Martinsberg [Pannonhalma]. Hier fand ich vier Testamente aus dem 17. Jahrhundert, die aus dem Dorf Kajár im Komitat Raab stammen. Nach gründlicher Erforschung der Dorfgeschichte konnte ich beweisen, dass vier Testatoren aus der gleichen Familie, und zwar aus aufeinander folgenden Generationen stammen. ${ }^{46}$ Das macht diese Quellen besonders interessant, weil ich bis jetzt ähnliche Dokumente in anderen Dörfern nicht finden konnte.

\footnotetext{
${ }^{45}$ HoRVÁTH, Nyúl község történetéhez.

${ }^{46}$ HORVÁTH, Monostorkörnyék falvainak.
}

In den Archiven von Ödenburg, Ungarisch Altenburg [Mosonmagyaróvár] und Weißbrunn [Veszprém] konnte ich mehr als 100 dörfliche Testamente finden, zumeist aus verschiedenen Orten.

Wenn man die formalen Eigenschaften der dörflichen Testamente aus der Frühneuzeit prüft, muss man darauf hinweisen, dass mehrere Testamente nur mündlich errichtet und erst später aufgeschrieben wurden. Der letzte Wille von Benedek Zöld, einem Leibeigenen aus der Gemeinde Nyúl, wurde erst nach seinem Tod aufgeschrieben. Das Raaber Domkapitel schrieb dessen letzten Willen in der Einzahl in der ersten Person im Januar 1586 vor sechs Zeugen nieder. ${ }^{47}$ Dass das Testament des Káptalanpatonaer Leibeigenen Mihály Nyírő noch existiert, verdanken wir der Tatsache, dass er es mündlich vor drei Zeugen errichtete. Diese wiederum fuhren nach Győr und liessen es durch das Domkapitel zu Papier bringen. ${ }^{8}$ Ähnlich ist der Fall des Miklós Németh. Er starb im Jahre 1732 in Petőháza, und sein mündlicher letzter Wille existiert in zwei verschiedenen schriftlichen Fassungen. Die erste stammt vom 15. Februar 1732, die zweite vom 8. Juni 1732. Der Inhalt der beiden Fassungen stimmt natürlich überein, aber auf die spätere wurde eine zusätzliche Bemerkung geschrieben, nämlich eine Bestätigung der Durchführung. ${ }^{49}$

Der Stil und die Ausarbeitung der schriftlich errichteten Testamente hängen im Wesentlichen von der Bildung der verfassenden Person ab. Die Testamente bestehen manchmal nur aus kurzen Absätzen, manchmal aus acht- bis zehnseitigen Erörterungen. Die Mehrheit der Testamente von Leibeigenen ist nur ein- bis zweiseitig, während die Testamente der dörflichen Kleinadeligen manchmal zehnseitig sind. Die

\footnotetext{
${ }^{47}$ HoRvÁTH, Nyúl község történetéhez 249-250.

${ }^{48}$ HoRváTH, Győri végrendeletek 1, 100.

${ }^{49}$ HorváTH, Falusi végrendeletek sajátosságai 359 360.
} 
dörflichen Testamente wurden vor fünf bis sieben Zeugen errichtet. Mindestens drei Zeugen waren es in allen Fällen, aber die längsten Namenverzeichnisse von Zeugen bestanden aus neun bis elf Namen. In den Namenslisten der Zeugen tauchen verschiedene Vorstände des Dorfes auf: Pfarrer, Richter, Notar, Schulmeister, Bergmeister und so weiter. ${ }^{50}$ Interessant ist, dass auch Frauen Zeuginnen waren. Nach der Meinung von Ernő Tárkány Szücs war das auch im 18. Jahrhundert ungewöhnlich. ${ }^{51}$

Die Zeugen versahen schon am Anfang des 17. Jahrhunderts die Testamente mit ihren Siegeln. Unterschriften von Zeugen sind bei dörflichen Testamenten aus dem 17. Jahrhundert aber selten und bleiben auch im 18. Jahrhundert untypisch. ${ }^{52}$ Die Mehrheit der Dorfbewohner konnte wahrscheinlich nicht schreiben. Das könnte die Erklärung sein, warum die Testamente der Dorfbevölkerung vor Glaubwürdigen Orten oder vor dem Gutsherrn entstanden. Ich habe bereits Beispiele von Leibeigenengemeinden des Raaber Domkapitels und der Benediktinerabtei Martinsberg erwähnt; man machte aber auch Testamente vor dem Raaber Domkapitel als Glaubwürdigem Ort. Von der Mitte des 18. Jahrhunderts an belebte sich die Tätigkeit auch im Prämonstratenserkonvent von Csorna: hauptsächlich die Kleinadeligen aus nähergelegenen Dörfern liessen sich hier ihren letzten Willen aufschreiben. ${ }^{53}$

Im Komitatsarchiv von Weißbrunn konnte ich mehrere Testamente aus dem 17. Jahrhundert in Abschriften aus dem 18. Jahrhundert finden. Das zeigt die Wichtigkeit des Inhalts dieser Testamente. ${ }^{54}$

Erwähnenswert ist, dass aus der Mitte des 18. Jahrhunderts mehrere dörfliche Testamente (zu-

${ }^{50}$ Ebd. 361-362.

51 TÁRKÁNY SZÜCS, Vásárhelyi testamentumok 170.

${ }^{52}$ HoRvÁTH, Falusi végrendeletek sajátosságai 362.

${ }^{53}$ Ebd.

${ }^{54}$ Ebd. 363. meist von Kleinadeligen) vorhanden sind, die von Ehefrau und Ehemann zusammen verfasst wurden. Beispiele für diese gemeinsamen Testamente finden wir auch in anderen Teilen des Landes. ${ }^{55}$

Von den inhaltlichen Eigenheiten der dörflichen Testamente möchte ich nur zwei interessante Punkte herausgreifen:

Die meisten konkreten Angaben beziehen sich auf fromme Vermächtnisse (pia legata). Fast alle Testamente enthalten mindestens ein frommes Vermächtnis, meistens an die Kirche des Dorfes. In der zweiten Hälfte des 17. Jahrhunderts erhöht sich die Zahl der Vermächtnisse, im 18. Jahrhundert sind sie auch schon in Testamenten von Leibeigenen üblich. Der Leibeigene István Tóth, der im Dorf Petőháza am Neusiedlersee im Jahre 1720 sein Testament errichtete, hinterließ der dortigen Kapelle, den beiden Kirchen der Nachbardörfer, der Kirche von Frauenkirchen [Boldogasszony], sowie den Kalvarien von Eisenstadt [Kismarton] fromme Vermächtnisse. Ebenfalls im Dorf Petőháza hinterließ Miklós Németh zwölf Jahre später neben den aufgezählten noch vier weiteren Kirchen pia legata. ${ }^{56}$ Neben den Kirchen der Nachbardörfer hinterließen die Testatoren Wallfahrtsorten die meisten frommen Vermächtnisse. Die Testatoren aus den Dörfern des Komitats Ödenburg bedachten neben Frauenkirchen oft die Franziskaner von Eisenstadt und manchmal auch die Kirche von Loretto. Ich halte Frauenkirchen für besonders wichtig, weil - wie aus der Studie von Norbert Frank $^{57}$ hervorgeht - die Tätigkeit der Franziskaner eine bedeutende Wirkung auf die Bevölkerung des westlichen Transdanubien hatte.

Die dörflichen Testamente enthalten viele Angaben im Zusammenhang mit den Begräbnissen. Ich habe diese Angaben bereits in einer

\footnotetext{
${ }^{55} \mathrm{Ebd}$.

${ }^{56}$ Ebd. 368.

${ }^{57}$ FRANK, Wallfahrt nach Frauenkirchen 71-83.
} 
Studie zusammengefasst, auf die ich hier nicht im Detail eingehen kann. ${ }^{58}$ Ich möchte aber darauf aufmerksam machen, dass ich einige Rechnungen von Begräbnissen als Beilagen von Testamenten fand. Die früheste derartige Angabe stammt aus der Raab benachbarten Gemeinde Nyúl aus dem Jahre 1649. Aus dieser Quelle wissen wir genau, wieviel Geld man für den Sargdeckel und für den Sargnagel aufwendete, was der Wein zum Totenmahl kostete, und welche Summe dem Pfarrer für das Begräbnis gegeben wurde..$^{59}$ Nach der Analyse der Rechnungen der Begräbnisse bekommen wir also ein Bild davon, was ein Leibeigener damals unter einem anständigen Begräbnis verstand und was er von seiner Umwelt erwartete.

\section{Literatur:}

Teréz CsÉcs, A Tudományos Gyüjtemény (1817-1841) repertóriuma (Győr 1998).

Istvánné CZÉGÉNY, Jászberényi végrendeletek a 18.19. századból (Szolnok 2001).

Péter DOMINKOVITS, Zwei Pfarrertestamente aus Hidegség. Angaben zur frühneuzeitlichen Sozialgeschichte des niederen katholischen Klerus der Diözese Raab, in: Felix TOBLER (Hg.), Bibliothekar und Forscher. Beiträge zur Landeskunde des burgenländisch-westungarischen Raumes. Festschrift für Norbert Frank zum 60. Geburtstag (Eisenstadt 2003) 41-56.

Péter DOMINKOVITS, Egy gazdag városvezető, Lackner Kristóf polgármester javai (Végrendeletek, hagyatéki- és vagyonleltárak, osztályok 1591-1632). Besitztümer eines reichen Stadtleiters, des Bürgermeisters Christoph Lackner (Testamente, Verlassenschafts- und Nachlassinventare, Vermögensteilungen 1591-1632) (Sopron 2007).

Norbert FRANK, Die Verbreitung der Wallfahrt nach Frauenkirchen an der Wende vom 17. zum 18. Jahrhundert. Beitrag zur Kirchengeschichte des burgenländisch-westungarischen Grenzraumes auf Grund einer Auswertung des Bruderschaftsbuches der Gürtelbruderschaft des heiligen Franziscus aus dem Franziskanerkloster Frauen-

\footnotetext{
${ }^{58}$ HORVÁTH, Végrendeleti adalékok.

${ }^{59}$ HORVÁTH, Győri végrendeletek 2, 150-151.
}

kirchen, in: Harald PRICKLER (Hg.), Burgenland in seiner pannonischen Umwelt. Festgabe für August Ernst (= Burgenländische Forschungen Sonderband 7, Eisenstadt 1984) 71-83.

Jenő HÁzI, Sopron szabad királyi város története. Teil II, Bd. 1: Végrendeletek és egyéb feljegyzések 1390-től 1524-ig (Sopron 1930).

Jenő HÁzI, Sopron szabad királyi város története. Teil II, Bd. 2: Végrendeletek, közgyűlési jegyzőkönyvek, polgárkönyvi feljegyzések és különféle számadások 1400-tó 1541-ig (Sopron 1931).

Ferenc M. HoRvÁTH, Váci végrendeletek Bd. 1: 17061750 (-1754) (Vác 2006).

József HORVÁTH, A győri végrendelkezők családi konfliktusai a 17. század első felében, in: László Á. VARGA (Hg.), Rendi Társadalom - polgári társadalom 3. Társadalmi konfliktusok (Salgótarján 1991) 233-244.

József HORVÁTH, Az 1600-1630 között keletkezett győri végrendeletek társadalomtörténeti adalékairól, in: Lajos DÁvID (Hg.), Arrabona 26-30. (Győr 1991) 45-77.

József HORVÁTH, Győr bírái a XVII. század első harmadában - végrendeleteik tükrében, in: Comitatus 2/10 (1992) 55-60.

József HoRvÁTH, Káptalanvisi végrendeletek a XVII. századból, in: Péter DOMINKOVITS, Éva TuRBULY (Hgg.), Házi Jenő Emlékkönyv (Sopron 1993) 267278.

József HORVÁTH, Temetkezési szokások kora újkori végrendeletek tükrében, in: Eszter KISBÁN (Hg.), Parasztkultúra, populáris kultúra és a központi irányítás. Tanulmányok (Budapest 1994) 197-212.

József HORVÁTH, Nyúl község XVII. századi történetéhez, in: Arrabona 34 (1995) 247-268.

József HORVÁTH, Győri végrendeletek a 17. századból, 3 Bde. (Győr 1995-1997).

József HoRVÁTH, A monostorkörnyék falvainak mindennapjai a 16-17. században, in: Imre TAKÁCS (Hg.), Mons Sacer 996-1996. Pannonhalma ezer éve. Bd. 2 (Pannonhalma 1996) 25-37.

József HORVÁTH, A XVII. század első felében keletkezett győri iparos végrendeletek kutatásának tapasztalataiból, in: Arrabona 36/1-2 (1998) 161-174.

József HORVÁTH, A falusi végrendeletek formai és tartalmi sajátosságai a Nyugat-Dunántúlon a 1718. században, in: Soproni Szemle 53 (1999) 356366.

József Horváth, Péter DominKovits (Hgg.), 17. századi Sopron vármegyei végrendeletek (Sopron 2001). 
József HoRVÁTH, Végrendeleti adalékok az Északnyugat-Dunántúl falusi temetkezési szokásainak kutatásához (1600-1850), in: Péter BerTA (Hg.), Halál és kultúra. Tanulmányok a társadalomtudományok köréből I. (Budapest 2001) 143-178.

József HORVÁTH, Végrendelkezés Halason (17001850), in: József Ö. KovÁCS, Aurél SzAKÁL (Hgg.), Kiskunhalas története 2. Tanulmányok Kiskunhalasról a 18.-19. századból (Kiskunhalas 2001), 495-518.

József HORVÁTH, Írásbeliség és végrendelkezési gyakorlat Győrben a XVII. században, in: Acta Papensia. A Pápai Református Gyüjtemények Közleményei 3/1-2 (2002) 81-98.

Tibor IVÁNYOSI-SZABÓ, Kecskeméti testamentumok, 4 Bde. (Kecskemét 2002-2004)

István KELEMEN, Sopron vármegyei jobbágyvégrendeletek a XVIII. század elejétől 1848-ig (Győr 2008).

János KEMÉNY, Duna-Tisza közi mezővárosi végrendeletek 1738-1847 (Kecskemét 2005).

Gyula KocsIs, 18. századi ceglédi végrendeletek, in: DERS. (Hg.), Ceglédi Füzetek 28. Történeti és néprajzi tanulmányok Ceglédről (Cegléd 1993) 531.

Gyula Kocsis, Hagyatéki iratok. Cegléd 1755-1820 (Cegléd 1997).

Ildikó KRISTÓF, „Rendeld el házadat, mert meghalsz”. A végrendelet készítés normái és formái a 16-17. századi falvakban és mezővárosokban, in: Katalin BENEDEK, Eszter CsONKA-TAKÁCs (Hgg.), Démonikus és szakrális világok határán. Mentalitástörténeti tanulmányok Pócs Éva 60. Születésnapjára (Budapest 1999) 521-556.

András KUBINYI, Főúri és nemesi végrendeletek a Jagelló-korban, in: Soproni Szemle 53 (1999) 331342.

Éva KujBus-MecseI, Nyíregyházi testamentumok 1789-1848. Forrásválogatás (Nyíregyháza 1995).

Mária LUPESCU-MAKó, Erdélyi késő középkori nemesi végrendeletek tárgytörténeti tanulságai, in: Sándor PÁL-ANTAL (Hg.), Emlékkönyv Kiss András születésének nyolcvanadik évfordulójára (Kolozsvár 2003) 317-330.

Judit MajOROSsY, A Krisztus Teste Konfraternitás helye a középkori pozsonyi polgárok életében, in: Enikő CsuKovits, Tünde LENGYEl (Hgg.), Bártfától Pozsonyig. Városok a 13-17. században (Budapest 2005) 253-291.

Mónika MÁTAY, Barta Gergely contra Zefer Mária. Egy XIX. századi válóper dilemmái, in: Zsombor BóDY, Mónika MÁTAY, Árpád TóTH (Hgg.), A mes- terség iskolája. Tanulmányok Bácskai Vera 70 . születésnapjára (Budapest 2000) 244-274.

Mónika MÁTAY, Egy gyưlölködő debreceni tímármester utolsó akarata, in: Zsolt K. HoRvÁTH, András LuGOSI, Ferenc SOHAJDA (Hg.), Léptékváltó társadalomtörténet. Tanulmányok a 60 éves Benda Gyula tiszteletére (Budapest 2003) 186-210.

Mónika MATAY, Historiográfiai viták a testamentumokról, in: Korall. Társadalomtudományi folyóirat 15-16 (2004) 248-270.

Mónika MATAY, Törvényszéki játszmák. Válás Debrecenben 1793-1848 (Debrecen 2006).

Gábor NÉMETH, Gyöngyösi testamentumok és fassiólevelek 1642-1710 (Eger 1991).

Gábor NÉMETH, Nagyszombati testamentumok a XVIXVII. századból (Budapest 1995).

Zoltán NÉMETH, Testamentumok, osztályos egyezségek Nyíregyházán 1759-1792 (Nyíregyháza 1987).

István RÁCZ, Debreceni végrendeletek 1595-1847 (Debrecen 1983).

Béla RADVÁNSKY, Magyar családélet és háztartás a XVI-XVII. században, 3 Bde. (Budapest 18791896).

László SOLYMOSI, Középkori végrendeleteink forrásértékéről, in: Tiszatáj 28/6 (1974) 26-29.

Anita D. SZAKÁCS, Medizingeschichtliche Testamente des 16.-18. Jahrhunderts. Gesellschaftsgeschichtliche Quellen des Sanitätswesens der Stadt Ödenburg aus der frühen Neuzeit. 16-18. századi orvostörténeti vonatkozású végrend.eletek. A kora újkori Sopron város egészségügyének társadalomtörténeti forrásai (Ödenburg-Sopron 2008).

Katalin SzENDE, A soproni késő középkori végrendeletek egyház- és tárgytörténeti tanulságai, in: Soproni Szemle 44 (1990) 268-273.

Katalin SZENDE, A soproni polgárság anyagi kultúrája a késő középkorban, in: Aetas 3 (1990) 69-123.

Katalin SZENDE, „es sey vil oder wenig, groß oder kchlain”. Besonderheiten und Unterschiede in der materiellen Kultur der Einwohnerschaft der königlichen Freistädte Preßburg und Ödenburg (1450-1490), in: András KUBINYI, József LASZLOVSKY (Hgg.), Alltag und materielle Kultur im mittelalterlichen Ungarn (Krems 1991) 108-118.

Katalin SzENDE, A nők szerepe a kézmüiparban a késő középkorban a soproni és pozsonyi végrendeletek tükrében, in: Péter DOMINKOvITS, Éva TURBULY (Hgg.), Házi Jenő Emlékkönyv (Sopron 1993) 169_ 179.

Katalin SzENDE, Handwerkerwitwen in der mittelalterlichen Gesellschaft von Ödenburg, in: Klára DóKA, István ÉRY (Hgg.), IV. Nemzetközi Kéz- 
műves-ipartörténeti Szimpózium (Veszprém 1994) 72-77.

Katalin SzENDE, Családszerkezet és örökösödési szokások a késő középkori Pozsonyban és Sopronban, in: Levéltári Közlemények 68 (1997) 77-98.

Katalin SzENDE, A magyarországi városi végrendeletek helye az európai joggyakorlatban. A középkori Sopron, Pozsony és Eperjes példája, in: Soproni Szemle 53 (1999) 343-356.

Katalin SzENDE, Otthon a városban. Társadalom és anyagi kultúra a középkori Sopronban, Pozsonyban és Eperjesen (Budapest 2004).
Ernő TÁRKÁNY SzÜCS, Vásárhelyi testamentumok (Budapest 1961).

Ernő TÁRKÁNY SZÜCS, A deficiens jobbágy végrendelete a 18-19. században, in: Agrártörténeti Szemle 8 (1966) 401-431.

Ernő TÁRKÁNY SZÜCS, Makói parasztok végrendeletei, in: Ethnographia 85 (1974) 493-512.

Ernő TÁRKÁNY SZÜCS, Jogi népszokások parasztságunk öröklési rendjében, in: Agrártörténeti Szemle 22 (1980) 273-310.

Kinga S. TüDÖs, Erdélyi testamentumok, 3 Bde. (Marosvásárhely 2003-2008). 